\title{
A Neurological Perspective upon Diabetes and Obesity, What They Are, and How They Can Be Measured
}

\author{
Graham Ewing \\ Mimex Montague Healthcare Limited, Mulberry House, NG12 3TU, 6 Vine Farm Close, Cotgrave, Nottingham, UK \\ Email: graham.ewing@mmhcl.co.uk
}

How to cite this paper: Ewing, G. (2018) A Neurological Perspective upon Diabetes and Obesity, What They Are, and How They Can Be Measured. Case Reports in Clinical Medicine, 7, 269-287. https://doi.org/10.4236/crcm.2018.74025

Received: March 5, 2018

Accepted: April 17, 2018

Published: April 20, 2018

Copyright $\odot 2018$ by author and Scientific Research Publishing Inc. This work is licensed under the Creative Commons Attribution International License (CC BY 4.0).

http://creativecommons.org/licenses/by/4.0/

\section{(c) (7) Open Access}

\begin{abstract}
New technologies bring new insights. The existence of the first mathematical model of how the brain regulates the autonomic nervous system and physiological systems, and knowledge of how this can be applied to screen or treat the diabetic, enables the author to take a comprehensive view of the etiology of diabetes and obesity. This paper illustrates the dynamic relationship between the brain, physiological systems and visceral organs. It highlights that 1) blood glucose is a neurally regulated physiological system, and/or network of organs, which function coherently in order to maintain blood glucose within normal physiological limits; and 2) that dysregulation of this physiological system (regulation of blood glucose levels), by genetic or phenotypic pathologies in the organs in this system, influences the prevailing levels of insulin, directly influences brain function and hence the coherent function of this and other physiological systems and organs e.g. blood pressure, sleep, $\mathrm{pH}$, digestion, sexual function, etc. In addition 3) the observation that proteins may be coiled and reactive, or uncoiled and resist reacting with their reactive substrates, leads to a greater level of understanding of the mechanisms responsible for type 2 diabetes and obesity and how such conditions could be screened and treated.
\end{abstract}

\section{Keywords}

Strannik, Mathematical Model, Autonomic Nervous System, Physiological Systems, Genotype, Phenotype

\section{Introduction}

New technologies bring new insights and so it is with the Strannik technology 
[1] which is based upon the observation that changes of colour perception have pathological coordinates. It is upon such observations that Dr I.G. Grakov [2] developed the first comprehensive mathematical model of how the brain regulates the autonomic nervous system [3] and physiological systems.

Grakov's mathematical model of the autonomic nervous system incorporates a precise level of understanding of the dynamic interplay between brain function, neural networks, and the parasympathetic nervous system and sympathetic nervous systems. These two fundamental mechanisms are perhaps more redolent of genotype and phenotype. The inflammatory response, which is primarily associated with the sympathetic nervous system, is often directly associated with elevated levels of intercellular acidity/pH which leads to the onset and progression of pathological processes. By comparison the parasympathetic response is directly associated with normal levels of intercellular $\mathrm{pH}$ and the base genetic level i.e. when the body rests, digests and recuperates. This article explores the many and various issues with particular emphasis upon the etiology of diabetes mellitus and obesity, inherent limitations therein, and how they can be screened and/or treated.

\subsection{Background}

Almost all medical conditions, drugs, vaccines, viruses, and stress are accompanied by changes to sense perception and, in particular, to colour perception. This arises because proteins and other biologically active materials emit biophotons of light following their reaction with their reactive substrates, typically enzymes or other proteins, and thereby influence colour perception [4]. It is the unique characteristics of this light, in particular its colour and intensity which are significant and illustrate the first example of a digital phenomenon which can be deployed to determine, in precise detail, the health of the patient i.e. for every pathological reaction there is the emission of a biophoton which is a direct measure of rate of reaction. This illustrates why the onset of diabetes is accompanied by the changes of blue-yellow colour perception [4] and/or the existence of an aura of light surrounding the body [5]. Moreover, by determining changes of colour perception and hence rate of reaction, such a technique appears to adopt a more precise, sophisticated and scientifically valid concept than any other diagnostic technique e.g. which are based upon measuring the level of biochemical markers [6].

This recognition, that proteins emit biophotons in the course of their reaction with their reactive substrates [4], illustrates that the body functions at a molecular level which can be detected from a level of magnitude of ca $7 \times 10^{2}$ biophotons per second i.e. the level at which the eye detects changes to colour perception, and is a direct reflection of rate of reaction. This contrasts with measurements of the prevailing systemic level of blood glucose at typically $4-8 \mathrm{mmol}$ per litre (which is effectively a measure of the glucose supplied from food vs glucose expended during exercise) i.e. the body functions as a biological reser- 
voir in which levels of all key physiological components are continuously being topped-up (or otherwise influenced) by various genetic and non-genetic (phenotypic) processes; however the rate of production of insulin and the rate at which insulin reacts with its receptor protein is far lower than their prevailing level in the body because glycogen and insulin are stored in the liver and pancreas respectively in readiness to support the metabolism of blood glucose and provide energy. See Figure 1.

This indicates the existence of a highly regulated neural mechanism: which continuously monitors and controls optimum levels of blood glucose between high and low limits; which incorporates an understanding of how the senses regulate the flow of food i.e. appetite and satiety; which incorporates the controlled release of glycogen and insulin; and which must also involve an understanding of the many and various factors which influence 1) the genetic expression of pre-pro-insulin and its subsequent conversion to the active coiled form of insulin (genotype) and 2) the magnesium-dependent reaction of insulin with its re-ceptor protein to influences the metabolism of blood glucose (phenotype) -often referred to as "insulin-resistance". These two indices, of genotype and phenotype, function in parallel with the overall systemic levels of blood glucose over a period and leads to similar diagnostic conclusions although in the short term levels of blood glucose are not stable and will invariably increase above and below accepted limits depending upon what the patient eats or drinks, and/or upon their exercise and/or experiences.

\subsection{Strannik Technology}

The Strannik software technology comprises two basic observations-one stemming from the other-which can be used to screen and/or treat the health of the patient: 1) that pathological reactions emit biophotons which influence colour perception, and 2) that the biological entity that we recognise as the brain functions as a neuromodulator which use sight and frequency to regulate the function of the autonomic nervous system and physiological systems i.e. the brain regulates the coherent function of the physiological systems, the organs

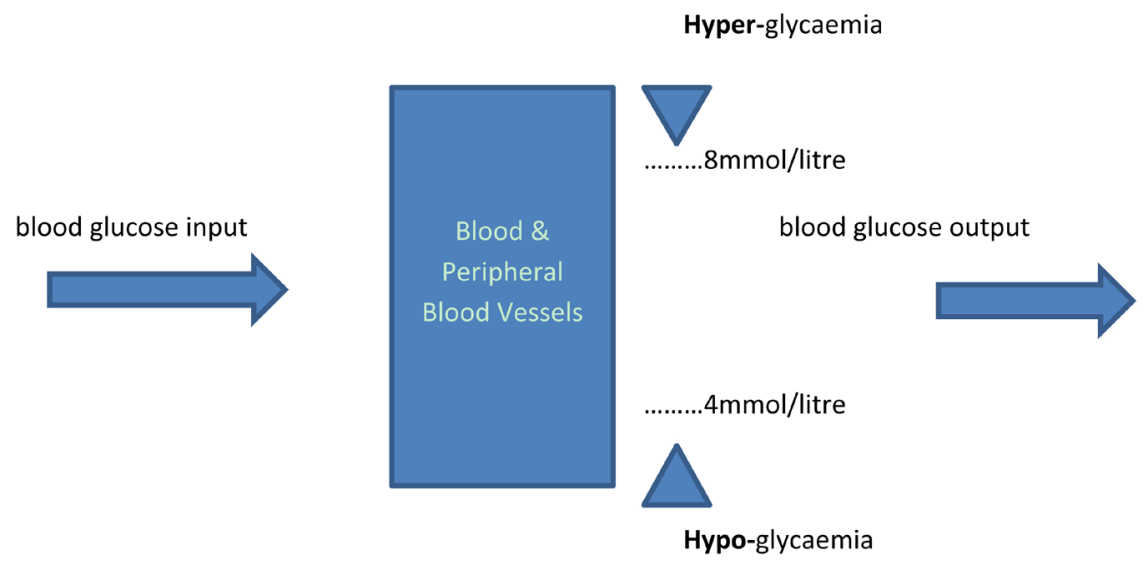

Figure 1. Blood glucose regulation. 
which are part of each system, the cells which are part of each organ, and the molecular processes which are part of each cell (see Figure 2). It enables the practitioner and/or the patient to screen the onset and progression of $5-15 \mathrm{pa}-$ thologies in each of the 30 main organs-with information about systemic stability, organ function, and cellular \& molecular biology - and then to deploy this information with therapeutic effect i.e. to treat autonomic dysfunction.

An accumulating body of evidence illustrates how this technology performs (as Strannik Virtual Scanning (SVS)) typically 2\% - 23\% more precisely than the current range of diagnostic technologies in use at various clinics and against which it was compared [7] [8] [9] [10]; and (as Strannik Light Therapy (SLT)) typically $83 \%$ - 96\% effective treating a wide range of medical conditions [7] [11] (See Case Studies 1 - 6): (Table 1).

Each SVS test is able to determine the precise physiological system which is most destabilised in the patient, the degree of changes to cell morphology in each organ, the precise pathology influencing each organ, each pathology being determined in terms of its genotype and phenotype i.e. typically 15 pathologies per organ in each and every of the 30 main organs. The technique is cognitive, digital and non-invasive, rapid (results in circa 20 minutes) and inexpensive (typically 5\% - 25\% the cost of contemporary diagnostic techniques [12]. It is the ideal technology for the patient to test themselves thereby enabling them to take responsibility for their health, to reduce the flow of patients to primary care, to reduce the flow of patients from primary care to secondary care and thence to tertiary care, to enable the patient to be tested and treated in confidence without risk of being stigmatised, etc.

In the diabetic patient the test results illustrate whether the condition is primarily type 1 or type 2 or whether it is a combination of both subtypes [13]. It also enables the diabetic patient to recognise how their diabetes is influencing, or being influenced by, the function of other organs e.g. the brain, heart, kidneys,

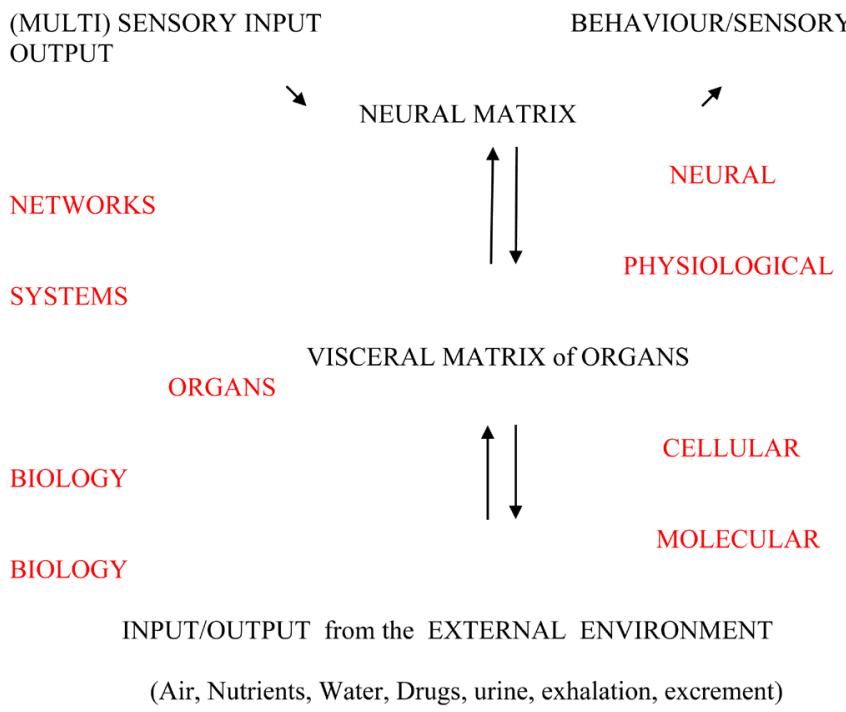

Figure 2. The Brain influences molecular biology and vice versa. 
Table 1. Case studies illustrating the value of strannik virtual scanning \& strannik light therapy.

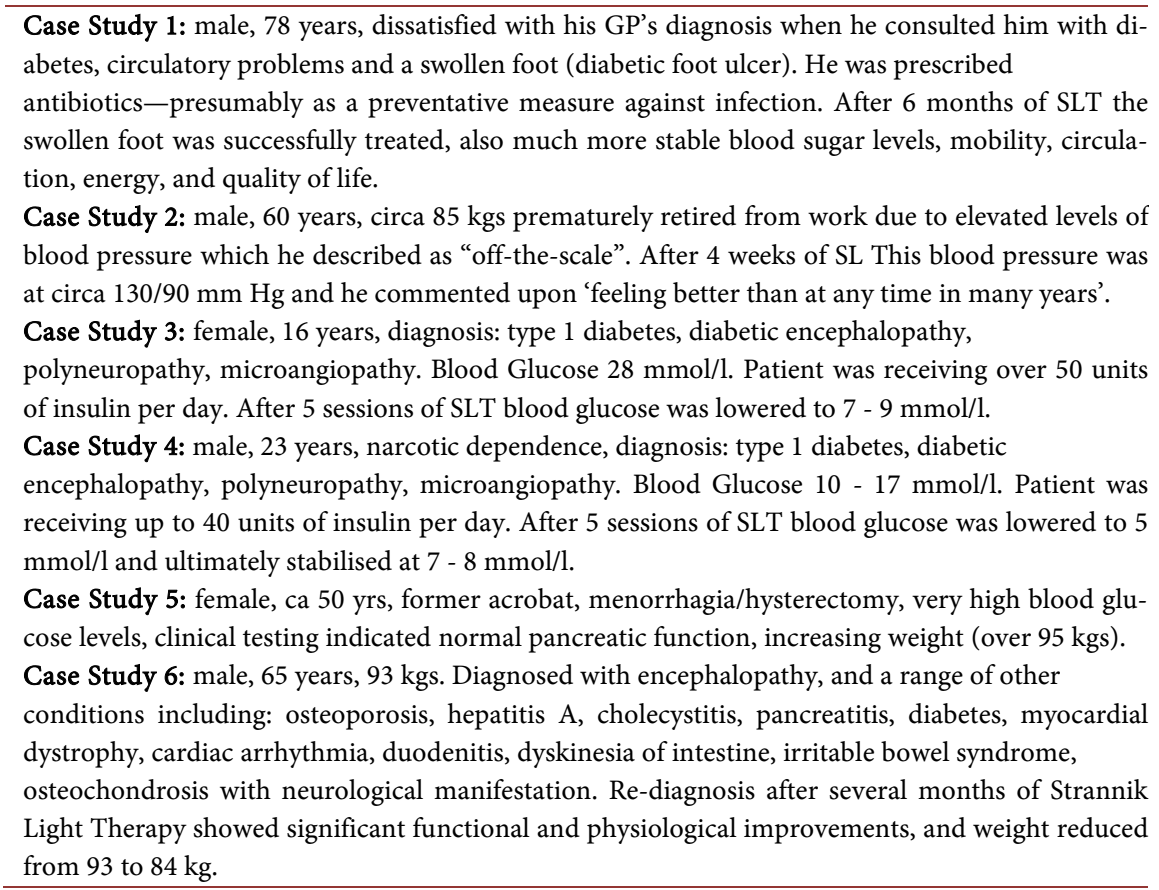

Note: case studies 1, 2 and 5 were noted in patient consultations conducted by Mimex Montague Healthcare during the period 2003-present; case studies 3, 4 and 6 were reported in studies conducted at clinics in Russia [7] [11].

peripheral nervous system, liver, adrenals, etc; and monitor the onset and progression of diabetic comorbidities in all other organs [14] [15] including what is increasingly considered as type 3 diabetes i.e. pancreatitis in the pancreas [16] [17].

As advised, an SVS report determines the genotype and phenotype for each pathology i.e. the reduced rate at which the genes express a particular protein (and hence its level) and the reduced rate at which the protein subsequently reacts. This enables us to determine the genetic and non-genetic (stress and/or environmental/phenotype/sympathetic) components in every pathology in every organ. It enables us to see the proportion of type 1 and type 2 diabetes in the diabetic patient (see Figure 3) and that both signals vanish if we give the patient an injection of insulin, at least until the effect of the injection wears off shortly thereafter. It enables us to see the influence of stress on patients with all manner of conditions i.e. that psychological and/or psychophysiological stress is the predominant factor in the disease process; and supports recent research which has shown that almost all diabetes has environmental and/or lifestyle origins [18].

\subsection{Interpretation of Results}

Each blue/red pair is indicative of the genetic or phenotypic characteristics of each pathology in each organ e.g. in the shown report-pancreas: diabetes, 


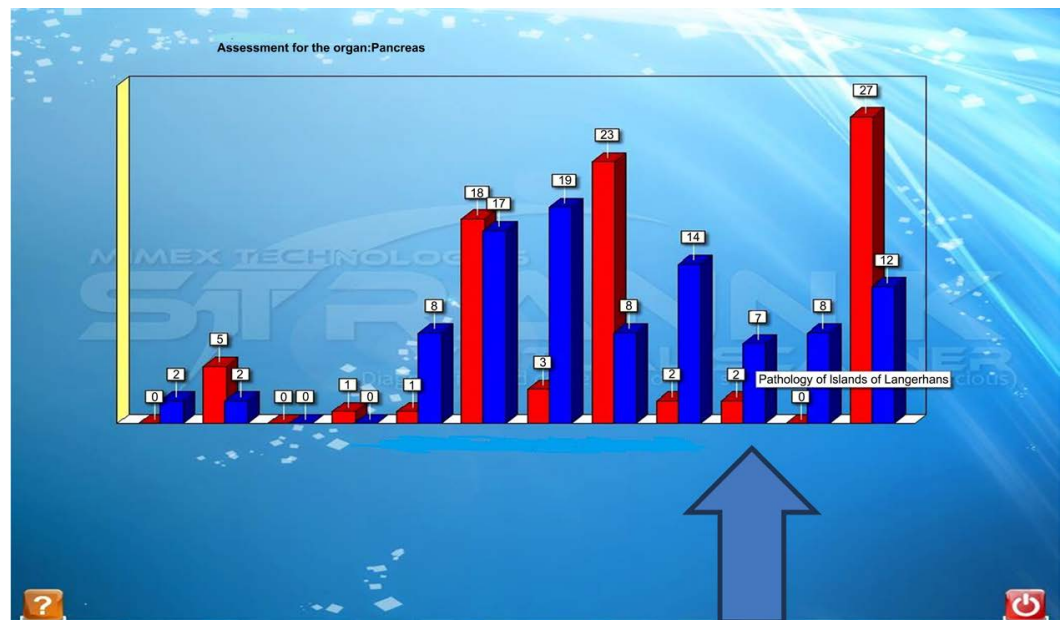

Figure 3. Strannik virtual scanning pathology report: pancreas.

pancreatitis, sclerosing pancreatitis, growth of new cells, allergic process, etc. The arrow illustrates the diabetes signal (denoted Pathology of Islets of Langerhans). A patient with 25 units (blue/genotype) would be experiencing significantly reduced expression of insulin. A patient with 25 units (red/phenotype) would be experiencing increased "insulin resistance" i.e. reduced levels of insulin reactivity. Patients with for example 20 units genotype and 28 units phenotype would be experiencing a combination of the two diabetic subtypes.

\section{Report}

Patient has reduced expression of insulin (7 units (blue)) and low phenotype (2 units (red)) which are at presymptomatic level (below 10 units) for both type 1 and type 2 diabetes.

Such a report enables the clinician to rapidly screen the patient and to recognise the mechanism which regulates the body's function and, in the diabetic patient, to recognise the factors which influence their regulation of blood glucose i.e. whether the condition directly influences 1) the genetic expression of pre-pro-insulin/insulin by the pancreas (genotype/epigenetics) due mainly to autoimmune destruction of pancreatic beta-cells, 2) the function of other organs which materially influence the regulation of the physiological system "blood glucose", or 3) whether instability in other regulated physiological systems (in particular sleep, $\mathrm{pH}$, sexual function) could influence function of the pancreas and 4) the production or reactivity of pre-pro-insulin/insulin. In addition this report highlights several case studies (Case Studies 1 - 4 \& 6) which illustrate how knowledge of this phenomena-how the brain regulates the autonomic nervous system and physiological systems -can be applied with therapeutic effect.

\section{Discussion of the Different Factors Which Influence the Onset of Diabetes}

In medical/genetic research this has immense implications. It enables the clini- 
cian to have an appreciation of 1 ) the rate at which proteins are genetically expressed; 2) the rate at which these genetically expressed proteins react with their reactive substrates; and 3 ) the many and various factors which influence the neural regulation of blood glucose e.g.

1) reduced protein expression is often considered to have genetic or epigenetic origins. Stress influences this process. It has been implicated in the epigenetic processes which accompany pathological onset and progression e.g. in type 1 and type 2 diabetes [19]. It influences brain function [20], memory [20], appetite [21] [22] and the cognitive response i.e. the ability of the brain to function and is associated with the regulatory and/or causal mechanism rather than the visceral or symptomatic consequences.

2) different genes cooperate together to express a particular protein e.g. pre-pro-insulin/insulin [23] [24].

3) The understanding that a single gene influences the expression of one particular protein has been shown to occur in very few medical conditions i.e. most "chronic" medical conditions are polygenomic, multisystemic and multi-pathological. See Figure 2 \& FIgure 3. Accordingly, in order to characterise a medical condition it is necessary to determine the complex morphology [25], energetics, genetic/epigenetic nature, systemic and pathological correlates of the condition from its earliest presymptomatic onset.

Over 40 genetic mutations are associated with the onset and progression of type 2 diabetes and collectively influence the expression of insulin in response to levels of carbohydrates, fats or proteins although such genetic changes are often reversible if the patient improves their lifestyle and diet.

Factors Influencing Genotype \& Phenotype:

a) The collective function of different genes/gene morphology

b) Genetic expression of Proteins

c) Rate of protein expression

d) Proteins convert to their active or inactive forms/protein morphology

e) Proteins react with their reactive substrates

f) Level of protein reactivity and rate of reaction

4) diabetes has multiple origins due to stress, lack of sleep [26] [27], consumption of acidified or alcoholic beverages, excess weight [28], lack of exercise, hyperindulgence [28], dehydration, etc. This is especially significant because sleep [29], $\mathrm{pH}$ [30], respiration, digestion and urination are neurally regulated physiological systems [29] [30] [31].

5) the endocrine glands, in particular the thyroid, pituitary and adrenal glands are common in 12 of the 13 physiological systems (see www.montaguehealthcare.co.uk/OperatingManual.pdf) and have a significant effect upon metabolic rate. Accordingly pathologies in any of these organs [32] [33] [34] must inevitably have a significant influence upon brain function and/or the brain's ability to regulate the autonomic nervous system and stable and/or coherent function of the physiological systems i.e. the brain adopts a best-fit model. 
6) different racial subtypes have a different spectrum of genes which function in a coherent manner to express pre-pro-insulin [24] [35] i.e. the genetic expression of a protein is influenced by genetic point defects but also by epigenetic effects. Accordingly, it is necessary to consider not just the chemical structure of the genes, which is significant, but also that the physical/spatial distribution of the genes/gene conformation [35] has a significant effect; therefore the addition or substraction of genetic components e.g. as a result of viral infection [36] or the influence of virus-like particles [37], increases or decreases the energetics of the DNA/genes and thereby increase or decrease the expression of the protein(s) e.g. pre-pro-insulin; and/or stimulate the function of antibodies [38] which adversely influence beta-cell function.

Jenner's observation that milkmaids exposed to cowpox did not subsequently develop smallpox illustrates the principle i.e. that viral RNA alters human DNA and subsequently our susceptibility to other viral infections and conditions. A wide range of viruses and virus-like particles have been shown to increase susceptibility to type 1 diabetes [35] [37] and in some cases to prevent susceptibility to type 1 diabetes i.e. that any changes to DNA have a direct or indirect influence upon genetic expression of proteins and must therefore influence to various extent the expression of different T-cells and other immune chemicals [25], and the subsequent formation of antibodies.

Moreover such a hypothesis considers the influence of genotype in isolation. It ignores the potential influence of phenotype (the sympathetic stress response) which influences levels of essential minerals, vitamins and cofactors; lowers levels of T-cells and immunochemicals in response to a particular stress or stressor [38] [39]; and facilitates the onset and progression of a particular viral infection, the direct or indirect establishment of an autoimmune response [25] and the subsequent development of type 1 diabetes.

In addition, any changes to genetic conformation as a result of the influence of gene-altering moieties must therefore influence the base genetic level of the parasympathetic nervous system.

7) the rate at which the expressed protein reacts is significant. Type 2 diabetes is generally referred to as "insulin-resistance" i.e. the insulin resists the process by which it reacts with its receptor protein however in chemistry the term "resistance" has no validity. Either the protein reacts or it does not react. Either way, the prevailing reaction conditions must also influence this process because proteins are polar which requires that we take into account whether the protein is able to react [30] [40] i.e. whether it is in its coiled reactive form or not (insulin-resistance, ghrelin-resistance [41], leptin-resistance [42]); and the factors which influence its subsequent reaction with its receptor protein(s) which, in the case of insulin, is a magnesium-dependent reaction.

As the prevailing levels of $\mathrm{Mg}, \mathrm{Zn}$ and Crare dependent upon acidity [30]] [40], $\mathrm{pH}$ must therefore be a factor in this coiling/uncoiling process [30] [40] [43] [44] [45]; in the retention of insulin (as the zinc-hexamer); and in the chromium-dependent cellular metabolism of blood glucose. Similarly, the ge- 
netic expression of proteins-proteins are polar-which depends upon magnesium and zinc to catalyse transcriptase enzymes must also be influenced by $\mathrm{pH} /$ acidity. If so, it is unlikely that protein misfolding would be restricted to just insulin [43] [44] [45] i.e. it would influence other proteins e.g. ghrelin, leptin, islet amyloid polypeptide [46], and susceptible proteins throughout the body. See Figure 4.

8) in addition alterations of intercellular $\mathrm{pH}$ and in particular changes to digestive acidity leads to the accumulation of organisms/bacteria which thrive at increased levels of acidity and which may also contribute to the onset of diabetes [47] although it remains unclear whether the presence of these organisms are the cause or consequence of increased acidity.

9) In cases of elevated fatty acid and lipid levels e.g. elevated BMI and/or obesity, lipids convert to fatty acids [48] and form long chain acyl-Co A which initiates the release of insulin. Increased levels of intercellular acidity, particularly so in the beta cells in the pancreas, destabilises the zinc-insulin hexamer and influences the ability of insulin to remain in its coiled reactive state. This depletes stores of insulin in the pancreas which is ultimately unable to sustain the supply of insulin, and/or sustain the pulsatile release of insulin [49]; which is, or becomes, unreactive (insulin resistance); and leads to elevated levels of blood glucose.

10) Light has a photo stimulating effect which increases the rate at which proteins react [50] i.e. light is a photoactivator which activates proteins and thereby stimulates a spectrum of biological processes. Although commonly associated
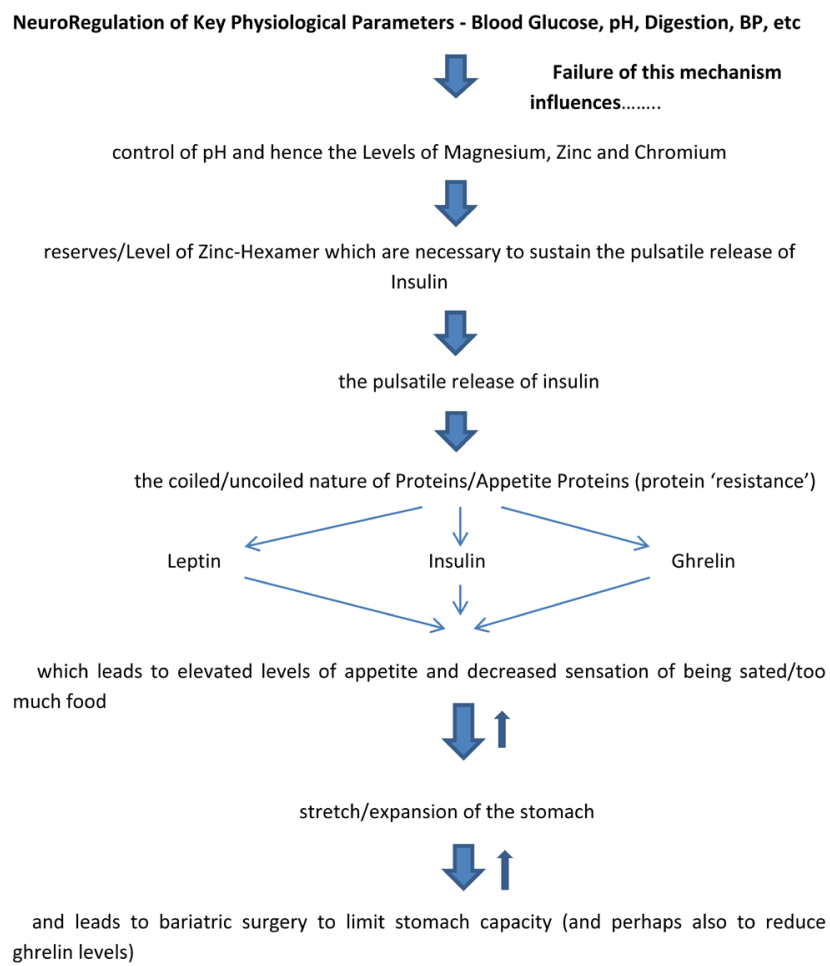

Figure 4. Neural regulation of blood glucose. 
with the production of vitamin D a considerable body of evidence [51] suggests that it is not solely associated with the production of vitamin D i.e. it influences brain function [52], the pineal and pituitary glands, heart function; the prevalence of type 1 diabetes, depression, multiple sclerosis (which illustrate latitude-dependent rates of occurrence); liver function; the levels of free radical scavengers (melatonin and serotonin), etc. Accordingly, the therapeutic application of light may have significant potential e.g. to stimulate the expression and/or reactivity of proteins. Moreover there is some evidence that the weight-reduction module of Strannik Light Therapy may have clinical application (see Case Study 6) re the treatment of diabetes and obesity.

11) the brain regulates the autonomic nervous system and the complex network of organs commonly referred to as the physiological systems. It does so by a circadian mechanism involving frequency i.e. it is a biochemical entity which functions in a biophysical manner to regulate the coherent function of networks of organs. Biochemistry alone is unable to explain this mechanism. Accordingly any changes to this process i.e. the ability of the brain to regulate the body's stability [53] e.g. resulting from stress; influences the stable and coherent function of the physiological systems (blood glucose, blood pressure, sleep and $\mathrm{pH}$ are neurally regulated physiological systems), the organs which are part of these systems [54], the cells which are part of these organs, and the molecular biology which influences cell function i.e. changes of genetic expression of proteins (epigenetics) and, in particular, of protein reactivity are the consequence of this process.

12) changes of brain function influence hormone levels and hormone reactivity (protein/hormone-"resistance") e.g. of insulin, leptin and ghrelin; in the brain and viscera; which are implicated in the regulated function of the digestive system, in particular which influence appetite and satedness and result in obesity.

13) although the administration of insulin is an invaluable aid to the type 1 diabetic it is significant that it does not prevent the onset or progression of comorbidities e.g. as stroke, neuropathy, heart attack, renal dysfunction, and retinal disease i.e. conditions which have multi-systemic, multi-pathological and poly genomic origins.

This illustrates why-for example females undergoing a hysterectomy (see Case Study 5) - will often develop non-pancreatic diabetes [55] i.e. their diabetes is not related to the function of their pancreas. Rarer forms of diabetes may be caused by hormonal abnormalities, inherited or developed genetic mutations, different morphologies and/or related metabolic imbalances [56]. This is immensely significant because it illustrates the problem of diabetes is associated with a wider phenomena involving a mechanism which regulates the stability and function of all physiological systems and, in particular re the case of hysterectomy [57], the influence of neural regulation of the endocrine glands [41] [54] [55] [56] [57] (adrenal, pituitary, thyroid) and sexual glands [58]. In particular, emergent comorbidities in any of the organs in each physiological system 
e.g. kidneys [59], liver [60], blood and peripheral blood vessels (manifest as diabetic foot/leg ulcers); will directly influence the stability of each neurally-regulated physiological system, and indirectly influence the stability of adjacent physiological systems (which can be measured by SVS).

Accordingly, there is a need to recognise and understand the scope of gene profiling when studying the many common ailments which routinely influence patient health; identify the complex range of factors are at play in each pathological process; and identify which genetic and/or epigenetic changes are the cause, or the consequence, of the systemic dysfunction leading to blood glucose instability i.e.

a) genetic, phenotypic, and/or pathological changes in the viscera influence brain function and, in particular, the sympathetic response.

b) during the development of diabetes the genetic profile alters from a normal genetic spectrum to the genetic spectrum which is typical of the diabetic patient however [61] if the patient takes efforts to incorporate an active lifestyle, alter their diet, and to manage their weight their genetic profile will revert to its normal pre-diabetic state i.e. genetic change is the consequence of this process.

c) it is not what the genes "are" which is significant-it is "what they do" and "the rate at which they do it" which is significant-to express proteins.

d) stress influences genetic/epigenetic expression of proteins. It is an acidifying process. Increased levels of acidity influences mineral levels, in particular of zinc and magnesium, and thereby lowers the genetic expression of proteins and inhibits the ability of blood glucose to react with its receptor protein (which is a magnesium-dependent reaction). Moreover acidity exhibits the characteristics of a neurally regulated physiological system which illustrates that, at least to some extent, the brain influences genetic expression of proteins.

e) any factors which influence gene profile e.g. viruses or virus-like vectors and/or particles which incorporate their vRNA into our DNA; and/or factors which adversely alter the shape of DNA [62] [63]; must inevitably influence, to a greater or lesser extent, the ability to express particular proteins e.g. the insulin precursor, and hence the prevailing levels of insulin.

f) it is what these expressed proteins do which is significant - to react with their reactive substrates.

$\mathrm{g})$ it is the rate of reaction of genetic and phenotypic reactions which is significant-not their level!

The SVS technology is the first medical technology to quantify these genetic and non-genetic components in terms of their ability 1) to express pre-pro-insulin/insulin, 2) of insulin to react with its receptor protein. It simplifies the process by which the clinician can precisely assess the health of the patient-effectively measuring genetic "supply" and phenotypic "demand".

\section{Summary and/or Conclusions}

Initial research [7] [9] [10] [11] has illustrated that SVS is ca $2 \%-23 \%$ more accurate than the range of diagnostic tests against which it was compared; that SLT 
is typically $83 \%$ - $96 \%$ effective (see Case Studies 1 - $4 \& 6$ ); that it can determine the complex pathological correlates of various multi-systemic and multi-pathological medical conditions e.g. migraine, Raynaud's phenomenon, Alzheimer's disease [15], cardiovascular disease(s) [14]; and has been successfully used to treat a wide range of ailments which have often defeated the best efforts of clinicians to bring relief to the patient e.g. dysarthria [64], sleep apnoea [65], migraine [66], dyslexia, diabetic foot ulcers, obesity, etc.

Over 100 medical conditions are known to respond to the beneficial effect of sunlight e.g. light has been shown to be a more effective treatment for seasonal-affective disorder than the antidepressant fluoxetine [67]. It is clear therefore that Strannik technology has considerable potential in the medical sphere and that SLT, in particular, is based upon an unprecedented level of understanding of how the brain regulates the autonomic nervous system, how this is influenced by sensory input, and influences measured parameters, in particular genotype and phenotype.

The author presents a coherent explanation for diabetes and obesity which appears to be consistent with all observed phenomena, in particular that changes of gene morphology [35] influence the genetic expression of pre-pro-insulin and hence the prevailing levels of insulin, that changes of intercellular acidity influence the ability of insulin to react with its receptor protein, that the brain regulates the coherent function of the autonomic nervous system and physiological systems, and that altered gene conformation influences the spectrum of antibodies and hence, at least in the beta-cells, the ability of the pancreas to produce and store insulin. In addition the observation that changes of intercellular acidity influence the ability of proteins to remain in a coiled reactive state leads to a plausible hypothesis for type 2 diabetes and obesity, in particular that protein uncoiling (leptin-resistance, insulin-resistance, and ghrelin-resistance) disrupts feelings of appetite and satedness which results in overload and subsequent enlargement and/or stretching of the stomach. This enlargement is dealt with by various methods of bariatric surgery in order to mechanically restrict the consumption of food in those who are unable to deal with this through self-control involving diet and exercise; however bariatric surgery can bring problems as the patient's physiology may occasionally be unable to adapt to the surgical alteration. The concept of neural regulation of physiological systems is a relatively radical departure from contemporary biomedicine but is not unexpected [68] [69] [70] or new e.g. leptin agonists have been developed which claim to reduce the patient's weight although the claims for such weight loss are often less than could be achieved if the patient was to employ psychological interventions e.g. attend weight-watching clinics.

This leads to a plausible explanation for those who are unable to successfully maintain a reduced weight [71] after dieting-their stomach remains in an enlarged state which is accompanied by dysfunctional levels of ghrelin and continued feelings of hunger-and illustrates the benefits of eating sufficient [72] [73] 
(the tradition of "harihachibu" employed by many Japanese which means "eat until you are $80 \%$ full") i.e. the avoidance of hyperindulgent bingeing behaviours.

There are many novel technologies in this emergent neurological paradigm although none which incorporate such comprehensive levels of understanding of what the brain does or how it does it. The concept upon which Strannik was based i.e. a mathematical model of the autonomic nervous system and physiological systems, was first conceived in the early 1980's [2]. It formed the basis of a screening and therapeutic technology which has been in the market since ca 1997 and incorporates a greater understanding of the complex mechanisms by which the brain functions [29] and upon which the European Commission created the Human Brain Project [74] [75] - which is based upon the same objectives as the Strannik technology-and which has sought to develop an essentially similar modality.

Moreover the initial indications, as outlined in this and other papers are that Strannik Virtual Scanning is able to screen for the emergence of type 1 and type 2 diabetes and complex variants thereof [7] [9] [10] [11] [76].

The research and medical community uses a rudimentary understanding of the body's stability (in particular of the body systems which are characterised by the terms "hyper"-function or "hypo"-function) as the basis of a medical examination and complements this with diagnostic tests to ascertain the nature of pathologies influencing patient health e.g. including genetic screening/genotype and the influence of our lifestyle/phenotype. This article advances this concept further to include a precise understanding of these structural relationships which, in this paper, seeks to advance the prevailing understanding for the pathological phenomena which are commonly known as "diabetes mellitus" and "obesity".

\section{Acknowledgements}

The author acknowledges the work of many researchers who, through their work, have made this article possible; also the research of Dr Igor Gennadyevich Grakov, developer of Strannik technology; and excellent support from Dr Syed Hasan Parvez, former head of the CNRS Neuroendocrine Unit, Paris.

\section{Conflict of Interest}

The author is CEO of Mimex Montague Healthcare, a company which is devoted to the future commercialisation of Strannik technology. The company is self-funded i.e. there has been no funding from any other source(s).

\section{References}

[1] Ewing, G.W., Ewing, E.N. and Hankey, A. (2007) Virtual Scanning-Medical Assessment and Treatment. Journal of Alternative and Complementary Medicine, 13, 271-286. https://doi.org/10.1089/acm.2006.5207

[2] Grakov, I.G. (1985) Strannik Diagnostic and Treatment System: A Virtual Scanner 
for the Health Service. Minutes of Meeting No. 11 of the Praesidium of the Siberian of the Academy of Medical Sciences of the USSR (AMN), Novosibirsk, 4 December 1985.

[3] Noseda, R., Lee, A.J., Nir, R.-R., Bernstein, C.A., Kainz, V.M., Bertisch, S.M., Buettner, C., Borsook, D. and Burstein R. (2017) Neural Mechanism for Hypothalamic-Mediated Autonomic Responses to Light during Migraine. Proceedings of the National Academy of Sciences, 114, E5683-5692.

https://doi.org/10.1073/pnas.1708361114

[4] Ewing, G.W., Parvez, S.H. and Grakov, I.G. (2011) Further Observations on Visual Perception: The Influence of Pathologies upon the Absorption of Light and Emission of Bioluminescence. The Open Systems Biology Journal, 4, 1-7.

https://doi.org/10.2174/1876392801104010001

[5] Kobayashi, M., Kikuchi, D. and Okamura, H. (2009) Imaging of Ultraweak Spontaneous Photon Emission from Human Body Displaying Diurnal Rhythm. PLos One, 4, e6256. https://doi.org/10.1371/journal.pone.0006256

[6] Deeny, S.R. and Steventon, A. (2015) Making Sense of the Shadows: Priorities for Creating a Learning Healthcare System Based on Routinely Collected Data. BMJ Quality \& Safety. https://doi.org/10.1136/bmjqs-2015-004278

[7] Vysochin, Y., et al. (2001) Methodology and Technology of Invigoration of Different Population Orders. In: Consolidated 5 Year Research Plan of Physical Training, Sports and Tourism State Committee of the Russian Federation. http://www.montaguehealthcare.co.uk/files/Vysochin/Vysochin.pdf

[8] Dooley, J., Tian, L., Schonefeldt, S., Delghingaro-Augusto, V., Garcia-Perez, J.E., Pasciuto, E., Di Marino, D., Carr, E.J., Oskolkov, N., Lyssenko, V., Franckaert, D., Lagou, V., Overbergh, L., Vandenbussche, J., Allemeersch, J., Chabot-Roy, G., Dahlstrom, J.E., Laybutt, D.R., Petrovsky, N., Socha, L., Gevaert, K., Jetten, A.M., Lambrechts, D., Linterman, M.A., Goodnow, C.C., Nolan, C.J., Lesage, S., Schlenner, S.M. and Liston, A. (2016) Genetic Predisposition for Beta Cell Fragility Underlies Type 1 and Type 2 Diabetes. Nature Genetics, 48, 519-527. https://doi.org/10.1038/ng.3531

[9] Ewing, G.W., Mohanlall, R. and Adams, J.K. (2017) A Clinical Study Report and Evaluation of the Ability of Strannik Virtual Scanning to Screen the Health of a Randomly Selected Cohort of 50 Patients. J Neurophysiol. Neurol. Disord., 4, 1-12.

[10] Ewing, G.W. and Duran, J.C. (2016) A Report of the Ability of Strannik Virtual Scanning to Screen the Health of a Randomly Selected Cohort of Patients. Enliven: Neurology and Neurotechnology, 2, 001.

[11] Ewing, G.W. (2017) A Summary or Meta-Analysis of Data Regarding the Use of Strannik Virtual Scanning as a Screening Modality for Healthcare. Asian Journal of Pharmacy, Nursing and Medical Science, 5, 55-71.

[12] Ewing, G.W. (2016) Further Perspectives on Diabetes: Neuroregulation of Blood Glucose. Neuroscience and Bio-Medical Engineering (NBE), 4, 1-9. https://doi.org/10.2174/2213385204666160510105701

[13] Ewing, G.W. and Parvez, S.H. (2010) The Multi-Systemic Nature of Diabetes Mellitus: Genotype or Phenotype? North American Journal of Medical Sciences, 2, 444-456. https://doi.org/10.4297/najms.2010.2444

[14] Ewing, G.W. and Ewing, E.N. (2009) Computer Diagnosis in Cardiology. North American Journal of Medical Sciences, 1, 152-159.

[15] Ewing, G.W. (2016) The Use of Strannik Virtual Scanning as a Modality for the Earliest Screening of the Pathological Correlates of Alzheimer's Disease. Human 
Frontier Science Program (HFSP) Journal, 10, 2-20.

[16] Mayor, S. (2017) Type 3c Diabetes Associated with Pancreatic Disease Is Often Misdiagnosed, Finds Study. British Medical Journal, 359, j4923.

https://doi.org/10.1136/bmj.j4923

[17] Woodmansey, C., McGovern, A.P., McCullough, K.A., Whyte, M.B., Muro, N.M., Correa, A.C., Gatenby, P.A.C., Jones, S.A. and de Lusignan, S. (2017) Incidence, Demographics, and Clinical Characteristics of Diabetes of the Exocrine Pancreas (Type 3c): A Retrospective Cohort Study. Diabetes Care, 40, 1486-1493. https://doi.org/10.2337/dc17-0542

[18] Dalgaard, K., Landgraf, K., Heyne, S., Lempradl, A., Longinotto, J., Gossens, K., Ruf, M., Orthofer, M., Strogantsev, R., Selvaraj, M., Tsai-Hsiu Lu, T., Casas, E., Teperino, R., Surani, M.A., Zvetkova, I., Rimmington, D., Tung, Y.C.L., Lam, B., Larder, R., Yeo, G.S.H., O’Rahilly, S., Vavouri, T., Whitelaw, E., Penninger, J.M., Jenuwein, T., Cheing, C.-L., Ferguson-Smith, A.C., Coll, A.P., Korner, A. and Pospisilik, A.J. (2016) Trim 28 Haploinsufficiency Triggers Bi-Stable Epigenetic Obesity. Cell, 164, 353-364. https://doi.org/10.1016/j.cell.2015.12.025

[19] Hagglof, B., Blom, L., Dahlquist, G., Lonnberg, G. and Sahlin, B. (1991) The Swedish Childhood Diabetes Study: Indications of Severe Psychologicalstress as a Risk Factor for Type 1 (Insulin-Dependent) Diabetes Mellitus in Childhood. Diabetologia, 34, 579-583. https://doi.org/10.1007/BF00400277

[20] McKim, D.B., Niraula, A., Tarr, A.J., Wohleb, E.S., Sheridan, J.F. and Godbout, J.P. (2016) Neuroinflammatory Dynamics Underlie Memory Impairments after Repeated Social Defeat. Journal of Neuroscience, 36, 2590-2604. https://doi.org/10.1523/JNEUROSCI.2394-15.2016

[21] Sinha, R. and Jastreboff, A.M. (2013) Stress as a Common Risk Factor for Obesity and Addiction. Biological Psychiatry, 73, 827-835. https://doi.org/10.1016/j.biopsych.2013.01.032

[22] Yau, Y.H.C. and Potenza, M.N. (2013) Stress and Eating Behaviours. Minerva Endocrinologica, 38, 255-267.

[23] Qi, Q., Wang, X., Strizich, G. and Wang, T. (2015) Genetic Determinants of Type 2 Diabetes in Asians. International Journal of Diabetology \& Vascular Disease Research.

[24] Bodhini, D., Radha, V., Ghosh, S., Majumder, P.P. and Mohan, V. (2011) Lack of Association of PTPN1 Gene Polymorphisms with Type 2 Diabetes in South Indians. Journal of Genetics, 90, 323-326. https://doi.org/10.1007/s12041-011-0060-3

[25] Wood, D.C., Veenstra, H., Khasnis, S., Gunnell, A., Webb, H.M., Shannon-Lowe, C., Andrews, S., Osborne, C.S. and West, M.J. (2016) MYC Activation and BCL2L11 Silencing by a Tumour Virus through the Large-Scale Reconfiguration of Enhancer-Promoter Hubs. eLife, 5, e18270. https://doi.org/10.7554/eLife.18270

[26] Broussard, J.L., Chapotot, F., Abraham, V., Day, A., Delebecque, F., Whitmore, H.R. and Tasali, E. (2015) Sleep Restriction Increases Free Fatty Acids in Healthy Men. Diabetologia, 58, 791-798. https://doi.org/10.1007/s00125-015-3500-4

[27] Yanping, L., Xiang, G., Winkelman, G.W., Cespedes, E.M., Jackson, C.L., Walters, A.S., Schernhammer, E., Redline, S. and Hu, F.B. (2016) Association between Sleeping Difficulty and Type 2 Diabetes in Women. Diabetologia, 59, 719-727. https://doi.org/10.1007/s00125-015-3860-9

[28] Caleyachetty, R., et al. (2017) "Healthy" Obese People Still at Higher Risk of Cardiovascular Disease Events than General Population. European Congress on Obe- 
sity, Porto.

[29] Ewing, G. (2016) What Is the Function of the Brain? What Does It Do and How Does It Do It? It Functions as a Neuroregulator, Which Continuously Regulates the Autonomic Nervous System and Physiological Systems, and Enables Us to Recognise that Sleep Exhibits the Characteristics of a Neurally Regulated Physiological System. Journal of Neurology and Psychology, 4, 9.

[30] Ewing, G.W. (2012) The Regulation of pH Is a Physiological System. Increased Acidity Alters Protein Conformation and Cell Morphology and Is a Significant Factor in the Onset of Diabetes and Other Common Pathologies. The Open Systems Biology Journal, 5, 1-12. https://doi.org/10.2174/1876392801205010001

[31] Ewing, G.W. and Ewing, E.N. (2008) Neuro Regulation of the Physiological Systems by the Autonomic Nervous System-Their Relationship to Insulin Resistance and Metabolic Syndrome. Biogenic Amines, 22, 208-239.

[32] Hage, M., Zantout, M.S. and Azar, S.T. (2011) Thyroid Disorders and Diabetes Mellitus. Journal of Thyroid Research, 2011, Article ID: 439463. https://doi.org/10.4061/2011/439463

[33] Pinto, J., Sudeep, K. and Venkatesha, B.M. (2014) A Rare Case of Type 1 Diabetes Mellitus with Pituitary Hypoplasia. Diabetology \& Metabolic Syndrome, 8, 184-186. https://doi.org/10.1016/j.dsx.2014.04.007

[34] Nestler, J.E. and McClanaghan, M.A. (1992) Diabetes and Adrenal Disease. Baillière's Clinical Endocrinology and Metabolism, 6, 829-847. https://doi.org/10.1016/S0950-351X(05)80169-7

[35] Ewing, G.W. (2017) The Interpretation of Genetic Data-Considering the Effect of Changes to Gene Conformation-If the Facts Don't Support the Theory, Change the Theory-How Does This Contribute to Understanding Diabetes? Journal of Genetic Disorders \& Genetic Reports, 6, 1-4.

[36] Filippi, C.M. and von Herrath, M.G. (2008) Viral Trigger for Type 1 Diabetes Pros and Cons. Diabetes, 57, 2863-2871. https://doi.org/10.2337/db07-1023

[37] Sanderson, N.S.R., Zimmermann, M., Eilinger, L., Gubser, C., Schaeren-Wiemers, N., Lindberg, R.L.P., Dougan, S.K., Ploegh, H.L., Kappos, L. and Derfuss, T. (2017) Co-Capture of Cognate and Bystander Antigens Can Activate Autoreactive B Cells. PNAS, 114, 734-739. https://doi.org/10.1073/pnas.1614472114

[38] Slota, C., Shi, A., Chen, G., Bevans, M. and Weng, N.-P. (2015) Norepinephrine Preferentially Modulates Memory CD8 T Cell Function Inducing Inflammatory Cytokine Production and Reducing Proliferation in Response to Activation. Brain, Behaviour, Immunity, 46, 168-179. https://doi.org/10.1016/j.bbi.2015.01.015

[39] Buck, M.D., O’Sullivan, D. and Pearce, E.L. (2015) T Cell Metabolism Drives Immunity. Journal of Experimental Medicine, 212, 1345-1360. https://doi.org/10.1084/jem.20151159

[40] Gunther, T. (2010) The Biochemical Function of $\mathrm{Mg}^{2+}$ in Insulin Secretion, Insulin Signal Transduction and Insulin Resistance. Magnesium Research, 23, 5-18.

[41] Naznin, F., Toshinai, K., ZavedWaise, T.M., Namkoong, C., Saleh MdMoin, A., Sakoda, H. and Nakazato, M. (2015) Diet-Induced Obesity Causes Peripheral and Central Ghrelin Resistance by Promoting Inflammation. Journal of Endocrinology, 226, 81-92. https://doi.org/10.1530/JOE-15-0139

[42] Myers, M.G., Leibel, R.L., Seeley, R.J. and Schwart, M.W. (2010) Obesity and Leptin Resistance: Distinguishing Cause from Effect. Trends in Endocrinology \& Metabolism, 21, 643-651. https://doi.org/10.1016/j.tem.2010.08.002

[43] Stefani, M. (2004) Protein Misfolding and Aggregation: New Examples in Medicine 
and Biology of the Dark Side of the Protein World. Biochimica et Biophysica Acta (BBA)-Molecular Basis of Disease, 1739, 5-25. https://doi.org/10.1016/j.bbadis.2004.08.004

[44] Wang, M. and Kaufman, R.J. (2016) Protein Misfolding in the Endoplasmic Reticulum as a Conduit to Human Disease. Nature, 529, 326-335. https://doi.org/10.1038/nature17041

[45] Damodaran, S. (2013) Electrodynamic Pressure Modulation of Protein Stability in Cosolvents. Biochemistry, 52, 8363-8373. https://doi.org/10.1021/bi400656a

[46] Mukherjee, A., Morales-Scheihing, D., Salvadores, N., Moreno-Gonzalez, I., Gonzalez, C., Taylor-Presse, K., Mendez, N., Shahnawaz, M., Fraga, D.W. and Soto, C. (2017) Induction of IAPP Amyloid Deposition and Associated Diabetic Abnormalities by a Prion-Like Mechanism. The Journal of Experimental Medicine, 214, 2591-2610. https://doi.org/10.1084/jem.20161134

[47] Vu, B.G., Stach, C.S., Kulhankova, K., Salgado-Pabón, W., Klingelhutz, A.J. and Schlievert, P.M. (2015) Chronic Superantigen Exposure Induces Systemic Inflammation, Elevated Bloodstream Endotoxin, and Abnormal Glucose Tolerance in Rabbits: Possible Role in Diabetes. MBio, 6, e02554.

https://doi.org/10.1128/mBio.02554-14

[48] Manukyan, L., Ubhayasekera, S.J.K.A., Bergquist, J. and Bergsten, P. (2015) Palmitate-Induced Impairments of Beta-Cell Function Are Linked with Generation of Specific Ceramide Species via Acylation of Sphingosine. Endocrinology, 156, 802-812. https://doi.org/10.1210/en.2014-1467

[49] Hellman, B., Gylfe, E., Grapengiesser, E., Dansk, H. and Salehi, A. (2007) Insulin Oscillations-Clinically Important Rhythm. Antidiabetics Should Increase the Pulsative Component of the Insulin Release. Lakartidningen, 104, 2236-2239.

[50] Mohr, S.B., Garland, C.F., Garland, F.C. and Gorham, E.D. (2008) The Association between Ultraviolet B Irradiance, Vitamin D Status and Incidence Rates of Type 1 Diabetes in 51 Regions Worldwide. Diabetology, 51, 1391-1398. https://doi.org/10.1007/s00125-008-1061-5

[51] Ewing, G.W. (2009) A Theoretical Framework for Photosensitivity: Evidence of Systemic Regulation. Journal of Computer Science and System Biology, 2, 287-297.

[52] Paul, K., Sengupta, P., Ark, E.D., Tu, H., Zhao, Y. and Boppart, S.A. (2017) Coherent Control of an Opsin in Living Brain Tissue. Nature Physics, 13, 1111-1116. https://doi.org/10.1038/nphys4257

[53] Ewing, G.W. and Parvez, S.H. (2011) Mathematical Modeling the Systemic Regulation of Blood Glucose: “A Top-Down” Systems Biology Approach. Neuro Endocrine Letters, 32, 371-379.

[54] Felšöci, M., Schroner, Z., Petrovičová, J. and Lazúrová, I. (2011) Relationship between Type 2 Diabetes Mellitus and Hypothalamic-Pituitary-Adrenal Axis. Wiener klinische Wochenschrift, 123, 28-33. https://doi.org/10.1007/s00508-010-1497-8

[55] Appiah, D., Winters, S.J. and Hornung, C.A. (2014) Bilateral Oophorectomy and the Risk of Incident Diabetes in Postmenopausal Women. Diabetes Care, 37, 725-733. https://doi.org/10.2337/dc13-1986

[56] Lenartowicz, B.B. and Snarski, E. (2012) Innovative Treatments in Diabetes Type 1. Journal of Diabetes and Metabolism, 3, 224. https://doi.org/10.4172/2155-6156.1000224

[57] Luo, J., Manson, J.E., Urrutia, R.P., Hendryx, M., LeBlanc, E.S. and Margolis, K.L. (2017) Risk of Diabetes after Hysterectomy with or without Oophorectomy in 
Postmenopausal Women. American Journal of Epidemiology, 185, 777-785. https://doi.org/10.1093/aje/kwx023

[58] Ricketts, H.T. (1952) Modern Treatment of Diabetes Mellitus. JAMA, 150, 959-961. https://doi.org/10.1001/jama.1952.03680100001001

[59] Pálsson, R. and Patel, U.D. (2014) Cardiovascular Complications of Diabetic Kidney Disease. Advances in Chronic Kidney Disease, 21, 273-280. https://doi.org/10.1053/j.ackd.2014.03.003

[60] Tolman, K.G., Fonseca, V., Dalpiaz, A. and Tan, M.H. (2007) Spectrum of Liver Disease in Type 2 Diabetes and Management of Patients with Diabetes and Liver Disease. Diabetes Care, 30, 734-743. https://doi.org/10.2337/dc06-1539

[61] Corella, D., et al. (2013) Mediterranean Diet Reduces the Adverse Effect of the TCF7L2-rs7903146 Polymorphism on Cardiovascular Risk Factors and Stroke Incidence. Diabetes Care, 36, 3803-3811. https://doi.org/10.2337/dc13-0955

[62] Rizvi, S., Raza, S.T. and Mahdi, F. (2014) Telomere Length Variations in Aging and Age-Related Diseases. Current Aging Science, 7, 161-167. https://doi.org/10.2174/1874609808666150122153151

[63] Eizirik, D.L., Sammeth, M., Bouckenooghe, T., Bottu, G., Sisino, G., Igoillo-Esteve, M., Ortis, F., Santin, I., Colli, M.L., Barthson, J., Bouwens, L., Hughes, L., Gregory, L., Lunter, G., Marselli, L., Marchetti, P., McCarthy, M.I. and Cnop, M. (2012) The Human Pancreatic Islet Transcriptome: Expression of Candidate Genes for Type 1 Diabetes and the Impact of Pro-Inflammatory Cytokines. PLOS Genetics, 8, e1002552. https://doi.org/10.1371/journal.pgen.1002552

[64] Ewing, G.W. (2015) The Successful Treatment of Dysarthria using Strannik Light Therapy (Biofeedback): A Case Study. Case Reports in Clinical Medicine, 4, 266-269. https://doi.org/10.4236/crcm.2015.47053

[65] Ewing, G.W., Nwose, E.U. and Ewing, E.N. (2009) Obstructive Sleep Apnea Management with Interactive Computer Technology and Nutrition: Two Case Reports. Journal of Alternative and Complementary Medicine, 15, 1379-1381. https://doi.org/10.1089/acm.2008.0630

[66] Nwose, E.U., Ewing, G.W. and Ewing, E.N. (2009) Migraine Can Be Managed with Virtual Scanning: Case Report. The Open Complementary Medicine Journal, 1, 16-18. https://doi.org/10.2174/1876391X00901010016

[67] Lam, R.W., Levitt, A.J., Levitan, R.D., Enns, M.W., Morehouse, R., Michalak, E.E. and Tam, E.M. (2006) The Can-SAD Study: A Randomised Controlled Trial of the Effectiveness of Light Therapy and Fluoxetine in Patients with Seasonal Affective Disorder. The American Journal of Psychiatry, 163, 805-812.

https://doi.org/10.1176/ajp.2006.163.5.805

[68] Glynn, P., Unudurthi, S.D. and Hund, T.J. (2014) Mathematical Modeling of Physiological Systems: An Essential Tool for Discovery. Life Science, 111, 1-5. https://doi.org/10.1016/j.lfs.2014.07.005

[69] Noble, D. (2015) Mathematics and Biology: The Ultimate Interface? Progress in Biophysics and Molecular Biology, 119, 205-207.

https://doi.org/10.1016/j.pbiomolbio.2015.09.002

[70] Kandel, E.R., Markram, H., Matthews, P.M., Yuste, R. and Koch, C. (2013) Neuroscience Thinks Big (and Collaboratively). Nature Reviews Neuroscience, 14, 659-664. https://doi.org/10.1038/nrn3578

[71] Iepsen, E.W., Lundgren, J.R., Holst, J.J., Madsbad, S. and Torekov, S.S. (2016) Successful Weight Loss Maintenance Includes Long-Term Increased Meal Responses of 
GLP-1 and PYY 3-36. European Journal of Endocrinology, 174, 775-784.

https://doi.org/10.1530/EJE-15-1116

[72] Willcox, D.C., Willcox, B.J., Todoriki, H., Curb, J.D. and Suzuki, M. (2006) Caloric Restriction and Human Longevity: What Can We Learn from the Okinawans? Biogerontology, 7, 173-177. https://doi.org/10.1007/s10522-006-9008-Z

[73] Willcox, B.J., Willcox, D.C., Todoriki, H., Fujiyoshi, A., Yano, K., He, Q., Curb, J.D. and Suzuki, M. (2007) Caloric Restriction, the Traditional Okinawan Diet and Healthy Aging: The Diet of the World's Longest-Lived People and Its Potential Impact on Morbidity and Lifespan. Annals of the New York Academy of Sciences, 1114, 434-455. https://doi.org/10.1196/annals.1396.037

[74] Ewing, G.W. and Grakov, I.G. (2015) A Comparison of the Aims and Objectives of the Human Brain Project with Grakov's Mathematical Model of the Autonomic Nervous System (Strannik Technology). Enliven: Neurology and Neurotechnology, 1,002 .

[75] Ewing, G.W. (2015) Back to Basics: Limitations of Research influencing the Human Brain Project. Computer Science \& Systems Biology, 8, 322-326.

[76] Woodmansey, C., McGovern, A.P., McCullough, K.A., Whyte, M.B., Munro, N.M., Correa, A.C., Gatenby, P.A.C., Jones, S.A. and de Lusignan, S. (2017) Incidence, Demographics, and Clinical Characteristics of Diabetes of the Exocrine Pancreas (Type 3c): A Retrospective Cohort Study. Diabetes Care, 40, 1486-1493.

https://doi.org/10.2337/dc17-0542 